\title{
Antirracismo, negritude e universalismo em Pele negra, máscaras brancas de Frantz Fanon
}

Gabriel dos Santos Rocha'

Resumo: Esta resenha tem como objetivo analisar Pele negra, máscaras brancas, livro de estreia de Frantz Fanon no campo das letras, abordando as análises do autor martinicano sobre desdobramentos do racismo e do colonialismo como formas de dominação entre os seres humanos no mundo moderno, e sobre parte dos debates teóricos e literários que impulsionaram a luta antirracista e anticolonial no contexto pós-segunda Guerra Mundial.

Palavras-chave:Frantz Fanon; racismo; colonialismo; antirracismo e anticolonialismo; eurocentrismo e negritude.

\begin{abstract}
This review aims to analyze Black Skin, White Masks, the first Frantz Fanon's book, in which the Martinican author analyzes the developments on racism and colonialism as forms of domination among humans in the modern world, and on part of the theoretical and literary discussions that boosted anti-racist and anti-colonial struggle in the post-second World War context.
\end{abstract}

Keywords: Frantz Fanon; racismo; colonialismo; anti-racism and anti-colonialism; eurocentrism and negritude

\section{INTRODUÇÃO}

Nas primeiras páginas do ensaio Pele negra, máscaras brancas, Fanon afirmou que pretendia tratar questões de tempo presente, delimitadas no espaço em que transitara o mundo francófono, porém, tratando-se de análises sobre fenômenos sociais ocorridos em diferentes partes do planeta - as relações assimétricas entre diferentes grupos humanos, marcadas principalmente pela questão racial - o autor considerou que o livro provavelmente contemplaria sociedades para além dos limites coloniais franceses. Fato que se consumou posteriormente, pois, o livro tornou-se um clássico do pensamento sobre a diáspora africana, do pensamento psicológico, dos estudos culturais e pós-coloniais - influenciou pensadores e militantes da descolonização dos países

1 Aluno de mestrado vinculado ao Programa de pós-graduação em História Social. Agência de fomento FAPESP. 
africanos - da teoria das ciências humanas, da filosofia e da literatura, estimulando obras influentes nestas áreas e no pensamento político e social ${ }^{2}$. Ao lado de Os condenados da Terra, concluído pelo autor em seus últimos dias de vida, Pele negra, máscaras brancas, influenciou diferentes gerações de militantes do movimento negro e da esquerda marxista não ortodoxa de diversas partes do mundo: Estados Unidos, América Latina e Caribe, Europa, África e, tardiamente, o Brasil.

Frantz Fanon nasceu em 20 de julho de 1925 na Martinica. Em sua juventude lutou junto às forças de resistência no norte da África e na Europa durante a Segunda Guerra Mundial sendo duas vezes condecorado com bravura. Estudou psiquiatria e filosofia na França, dirigiu o Departamento de Psiquiatria do Hospital Blida-Joinville na Argélia (hoje renomeado como Hospital Frantz Fanon), tornou-se membro da Frente de Libertação Nacional da Argélia, dedicou-se à luta contra o colonialismo e o racismo no mundo moderno. Entrou para a lista de procurados em todo território francês. Morreu em 6 de dezembro de 1961 nos Estados Unidos enquanto se tratava de leucemia ${ }^{3}$. O conjunto de sua obra ${ }^{4}$ é dedicado aos estudos culturais do mundo colonial do século XX, refletindo sobre as possíveis vias de descolonização dos povos. O autor demonstra claramente sua orientação pelo materialismo histórico quando considera que uma revolução não se faz através da cultura, mas através da transformação das condições materiais a partir das quais a cultura se torna possível. Deste modo, Fanon afirma que uma revolução cultural deve ser também uma revolução social que transforme todas as estruturas do sistema político e econômico vigente, portanto, a luta dos negros deve estar alinhada com a luta anticapitalista, e contra todas as formas de opressão existentes ${ }^{5}$. Sua obra demonstra que a luta contra a opressão no mundo colonial deve abranger a totalidade das condições em que a opressão se manifesta, considerando fatores psicológicos, contexto histórico e social, sistema político e econômico. É preciso descolonizar as nações, mas também os seres humanos. Descolonizar é criar homens novos, modificar fundamentalmente o ser, transformar espectadores em atores da história ${ }^{6}$.

2 GORDON, Lewis R. , "Prefácio” in: FANON, Frantz, Pele negra, máscaras brancas. 2008. P.13

3 GORDON, Idem. P.13

4 Em seus 36 anos de vida, com uma carreira de escritor iniciada aos 25 anos, Frantz Fanon teve quatro livros publicados em vida: Peau noire, masque blancs (1952); L'an V de la révolution algérienne (1959); Le damnés de la Terre (1961). E uma publicação póstuma: Pour la révolution africaine (1964).

5 FANON, Frantz. Os condenados da Terra. P. 267

$6 \quad$ FANON. Idem. P. 52 


\section{AS IDEIAS DE FANON NO BRASIL.}

No Brasil houve um silêncio sobre a obra deste autor até meados dos anos 1960 . Suas ideias chegaram aqui em uma época de disputa entre o marxismo e o existencialismo na cena cultural e política, e como quase todas as ideias novas daquela época, chegaram através de livros europeus $^{7}$, nos mostrando como boa parte das elites intelectuais brasileiras durante muito tempo ignorou não apenas a questão do racismo, como também o que foi produzido intelectualmente fora do eixo Europa e Estados Unidos. O sociólogo Antonio Sérgio Guimarães afirma que certamente a esquerda brasileira tomou conhecimento de Fanon através do extrato de Damnés de la Terre (1961), publicado na revista Les Temps Modernes, e do prefácio que Sartre escreveu para esta obra. As ideias de Fanon chegam ao Brasil num momento em que pensar a revolução social estava na ordem do dia, porém, passada esta fase, ao contrário do que ocorreu em outros lugares, as ideias do autor não foram objeto de reflexão exegética e crítica por parte de universitários e acadêmicos estabelecidos em centros de estudos ${ }^{8}$.

Paulo Freire talvez tenha sido o primeiro intelectual brasileiro de grande reconhecimento a abraçar as ideias de Fanon, referências ao autor martinicano e citações de Os Condenados da Terra aparecem em Pedagogia do Oprimido, escrito entre 1965 e 1968 durante o exílio no Chile ${ }^{9}$. Lewis R. Gordon no prefácio para a edição brasileira de Pele negra, máscaras brancas também afirma: “(...) uma leitura cuidadosa de Pedagogia do Oprimido de Paulo Freire revela o quanto esta obra sofre influência de Fanon” ${ }^{10}$.

Em 1968 foi lançada a primeira edição brasileira de Os condenados da Terra, porém, rapidamente tirada de circulação pelos órgãos da repressão. Neste mesmo ano Abdias do Nascimento parte para os Estados Unidos onde permaneceu exilado até 1981, é neste período que o líder do Teatro Experimental do Negro entra em contato com a obra de Frantz Fanon, amplamente traduzida, discutida e comentada naquele país, onde influenciou intelectuais e militantes comprometidos com a causa antirracista e com a revolução social, entre os quais, os Panteras Negras. Fanon passa a ser referido na obra de Nascimento a partir de O genocídio do negro

7 GUIMARÃES, Antonio Sérgio A., “A recepção de Fanon no Brasil e a identidade negra.” in: Novos Estudos, 8 de julho de 2008. P. 99-100

8 GUIMARÃES. Idem. P. 100-103

9 GUIMARÃES. Ibidem. P. 106

10 GORDON. P. 11 
brasileiro, lançado em meados dos anos 1970 (Guimarães p. 105-106), suas ideias também marcaram os discursos dos jovens estudantes que incorporaram as fileiras do movimento negro brasileiro nas décadas de 1970 e 1980, entre eles os fundadores do Movimento Negro Unificado $(\mathrm{MNU})^{11}$.

\section{UM OLHAR SOBRE PELE NEGRA, MÁSCARAS BRANCAS}

Pele negra mascaras brancas, trata-se de um ensaio interdisciplinar, pois transcende as fronteiras acadêmicas: tem forte caráter sociológico, epistemológico, político e poético (o poeta e militante martinicano Aimé Césaire, ligado à negritude e ao surrealismo, é supracitado), se utiliza da psicanálise, faz análises clínicas, sócio diagnósticos, analisa também obras literárias e cinematográficas ${ }^{12}$, propondo um conjunto de mecanismos retóricos que implementam diferentes maneiras de abordar um problema, a saber: as relações entre negros e brancos pautadas pelo racismo. O livro foi escrito quando o autor tinha 25 anos de idade e publicado quando tinha 27. Originalmente seria sua tese de doutorado em psiquiatria, recusada pelos membros da banca julgadora. Fanon obteve doutorado com outra tese, mas em 1952 conseguiu publicar o texto que havia sido recusado ${ }^{13}$.

As análises psicológicas feitas pelo autor consistem em sócios diagnósticos, através dos quais se entende que a alienação do negro não é apenas uma questão individual, e sim um fenômeno socialmente construído, que opera como importante mecanismo do colonialismo ${ }^{14}$, ou seja, funciona como engrenagem de um sistema político capitalista, sendo o racismo também, para além dos domínios coloniais, um mecanismo de distribuição de privilégios em sociedades marcadas pela desigualdade.

Entre as fontes que o autor utiliza neste estudo estão laudos clínicos psiquiátricos, pesquisas de campo entre um público diverso das Antilhas e da França (em grande parte estudantes e operários), obras literárias, cinematográficas e anúncios publicitários do mundo francófono.

11 GUIMARÃES. Op. Cit.. P. 105, 106, 110

12 SILVEIRA, Renato. "Nota do tradutor” in: FANON, Frantz, Pele negra, máscaras brancas. P. 8

13 GORDON, Op. Cit.. P.13

14 FANON, Pele negra máscaras brancas. P. 29 
Porém tais fontes são mencionadas na introdução e aparecem ao longo do ensaio, não havendo uma lista de documentos e bibliografia no final do texto. No caso das entrevistas e dos laudos clínicos, o autor também dispensou o uso de tabelas e gráficos indicando percentuais de entrevistados ou pacientes.

No mundo latino - francófono, lusófono e hispânico - dos anos 1950 o racismo era considerado uma doença peculiar das sociedades anglófonas: Estados Unidos, Grã-Bretanha, Austrália, África do Sul ${ }^{15}$. Contrariando tal pensamento, este livro nos mostra como a ideologia da suposta igualdade racial pode dar suporte para que o racismo se manifeste de maneira “velada”. Ser indiferente à existência do racismo, em sociedades multirraciais onde as relações sociais são marcadas principalmente pela assimetria entre os diferentes grupos étnicos significa dar suporte para quem detém a hegemonia, no caso das sociedades estudadas por Fanon, os brancos. O autor vê incoerência em comparar racismos de diferentes sociedades para dizer que o racismo de uma é pior do que o de outra ${ }^{16}$. Apesar das diferentes formas em que se manifesta, o racismo nas sociedades latinas é tão perverso quando no mundo anglófono, pois em todos os casos funcionará como mecanismo de exclusão social dos negros.

Embora as análises do autor sejam elucidativas para compreendermos as mais diversas formas de dominação e opressão sociais e políticas, o fio condutor das discussões privilegia o estudo do racismo no contexto colonial francês de meados do século $\mathrm{XX}^{17}$. Para Fanon a colonização não se limita à subordinação material de um povo, pois ela também fornece os meios pelos quais as pessoas são capazes de se expressarem e se entenderem, estando, portanto, no cerne da linguagem, nos métodos pelos quais as ciências são construídas, na produção cultural como a literatura, o teatro e o cinema.

O complexo de inferioridade do colonizado deve-se ao sepultamento de sua originalidade cultural, faz parte do processo de dominação colonial desconsiderar que o negro possui cultura, civilização e um longo passado histórico. Ao analisar criticamente o colonialismo, o autor também volta sua atenção para formas de reação e resistência contra a dominação europeia, estabelecendo ao longo do livro um diálogo com autores da négritude, dentre eles, Alione Diop, Leopold Senghor e René Maran. As principais ideias discutidas sobre esses autores dizem respeito à

15 GORDON, Op. Cit.. P. 13

16 FANON, 2008. P. 84-86

17 O livro foi publicado sete anos após o término da segunda guerra mundial. 
reconstrução da história, da civilização e de uma cultura negra original como forma de restituir a identidade do negro suprimida pelo colonialismo. Voltaremos a esse ponto mais adiante.

Entre os temas discutidos no livro está o papel da linguagem na construção de relações de dominação colonial, onde é analisado o status que a língua e a cultura do colonizador assumem no cotidiano dos colonizados e nas relações destes com os colonizadores. O autor considera que "falar é existir absolutamente para o outro" e o colonialismo faz com que o negro tenha duas condições de existência: uma para o branco, outra para o seu semelhante. "Um homem que possui a linguagem possui, em contrapartida, o mundo que esta linguagem expressa e que lhe é implícito.” ${ }^{18}$ Nas colônias antilhanas o domínio da língua francesa funciona como forma de aproximação entre o negro e o mundo dos brancos, que se impõe como o “mundo civilizado.” Na medida em que o colonizado assimila os valores culturais da metrópole, ele supostamente estará escapando do que o colonizador chamou de “selva,” neste caso comunicar-se nas línguas crioulas seria uma das marcas de “selvageria.” É comum que esta “assimilação cultural” afaste o negro antilhano de seus semelhantes, e o desloque de seu grupo de origem.

No contexto colonial, tanto nas Antilhas, quanto nos países africanos, o negro que detém a cultura do colonizador se eleva em seu grupo social, porém, nunca se equipara ao branco. A língua funciona como porta de entrada aos valores do colonizador transmitidos através da cultura: literatura, filosofia, conhecimento científico, onde são enaltecidos os feitos históricos, o progresso, as conquistas, em geral, exemplos que demarquem a pretensa superioridade do europeu sobre os outros povos justificando sua hegemonia perante o mundo. Por outro lado, a valorização superestimada da cultura europeia, se fortalece na desvalorização das culturas dos negros, ou simplesmente, na total destituição cultural do colonizado, ou seja, na indicação de que há ausência de civilização entre os povos colonizados. Fanon tece críticas ao colono branco que impõe sua cultura e aos membros da pequena burguesia Antilhana que aderem aos hábitos europeus como forma de distinguirem-se de seu grupo étnico de origem, marcando assim uma ascensão social via “embranquecimento cultural.” Fanon salienta ao longo do livro que sua luta não é contra o homem europeu, nem contra a cultura europeia, mas contra os mecanismos políticos e ideológicos do colonialismo que hierarquizam os seres humanos e as diferentes culturas.

No segundo e no terceiro capítulo intitulado respectivamente "A mulher de cor e o branco”, “O homem de cor e a branca”, o autor continua analisando vias de embranquecimento 
tentativas de aceitação dos negros no mundo dos brancos através da união conjugal ou das relações sexuais, apontando que a presença da união matrimonial inter-étnica e da miscigenação não excluem a existência do racismo, não havendo necessariamente uma incompatibilidade entre ambos. Fanon nos mostra o complexo de inferioridade introjetada na psique de um negro ou uma negra pode influenciar na escolha do cônjuge privilegiando o branco ou a branca como parceiros ideais, tanto pela questão estética, que em sociedades racistas define-se o padrão de beleza branco como o belo por excelência, quanto pela questão material, pois, nestas mesmas sociedades a cor também se torna um marcador da distribuição de privilégios colocando os brancos no topo da pirâmide. Nestes dois capítulos, além de utilizar fontes orais, o autor se respalda sobre a crítica de dois romances de autores antilhanos: Je suis martiniquaise de Mayotte Capécia, para a relação homem branco/mulher negra, e Un homme pareil aux autres de René Maran para a relação homem negro/mulher branca ${ }^{19}$.

Fanon entende que o racismo alia-se às barreiras econômicas como forma de garantir os privilégios das elites brancas, também funcionando como proteção aos brancos pobres, impedindo-os de decaírem ainda mais na pirâmide social ${ }^{20}$. O racismo deve ser combatido como uma forma de opressão aliada à exploração econômica, e a manutenção das estruturas sociais. Tanto o materialismo histórico de Marx quanto a influência de ideias de Hegel, faz com que Fanon inclua a libertação do negro em um projeto universalista de libertação, considerando que todas as formas de exploração tem uma semelhança em comum, pois são aplicadas a um mesmo objeto: o ser humano. Esta tendência ao universalismo revelada desde a introdução do livro torna-se mais enfatizada do quarto capítulo em diante. Escrevendo no contexto imediato ao pós-segunda guerra, e ao holocausto de judeus, o autor frequentemente faz referência à questão do antissemitismo reforçando sua mensagem de solidariedade entre os oprimidos do mundo na luta contra todas as formas de opressão.

O racismo impõe aos indivíduos desvios existenciais: "aquilo que se chama de alma negra é frequentemente uma construção do branco"²1, do mesmo modo o suposto caráter negativo atribuído aos judeus resulta de construções do antissemita ${ }^{22}$. Os estigmas construídos aos grupos

19 Não entraremos em detalhes da análise do autor sobre estas duas obras para não nos perdermos do objetivo desta resenha que é uma análise geral dos principais temas do livro.

20 FANON, 2008. P. 87

21 Idem. P. 30

22 Ibidem. P. 90 
que se tornam bode expiatório em sociedades racistas são veiculados em ditados populares correntes no cotidiano, nas escolas, livros didáticos, histórias em quadrinhos, periódicos, literatura, cinema, teatro. O racismo e a colonização extirpam do negro qualquer aspecto de valor e originalidade. Diante disso, Fanon critica os negros que buscam o caminho do embranquecimento como tentativa de ilusoriamente atenuar sua situação de oprimido.

Em oposição ao racismo e a via do embranquecimento estiveram os intelectuais da négritude, já mencionados anteriormente. Aqui nos referimos ao movimento literário dos anos 1940 e 1950 integrado pelos intelectuais negros, em geral poetas e romancistas originados das excolônias francesas africanas e caribenhas, situados em Paris em torno da revista Présence Africaine. Segundo o antropólogo Kabengele Munanga:

\begin{abstract}
A negritude nasce de um sentimento de frustração dos intelectuais negros por não terem encontrado no humanismo ocidental todas as dimensões de sua personalidade. Nesse sentido, é uma reação, uma defesa do perfil cultural do negro (...) uma recusa da assimilação colonial, uma rejeição política, um conjunto de valores do mundo negro, que devem ser reencontrados, defendidos e mesmo repensados. Resumindo, trata-se primeiro de proclamar a originalidade da organização sociocultural dos negros, para depois defender sua unidade através de uma política de contraaculturação, ou seja, desalienação autêntica ${ }^{23}$.
\end{abstract}

A negritude nasce como uma reação ao racismo do branco, e uma negação à via do embranquecimento, através da afirmação de uma cultura negra dotada de originalidade e valores positivos. Fanon dialoga com tais ideias ao longo do ensaio tecendo críticas ao que ele vê como um essencialismo negro contido no discurso de alguns autores da negritude, e olha com desconfiança para qualquer busca de "um ser tipicamente negro", ou de uma cultura negra que se sobreponha às várias culturas negras existentes. Um aspecto para o qual o autor chama a atenção consiste na armadilha de se construir uma identidade negra centrada na emoção, criticando, deste modo, uma afirmação atribuída a Leopold Senghor onde a “razão é grega e a emoção é negra”. O problema de uma negritude baseada neste tipo de essencialismo estaria no fato de querer construir uma identidade negra a partir de estereótipos criados pelos brancos para afirmar sua suposta superioridade ${ }^{24}$. Para o autor, atribuir a emoção ao negro e a razão ao branco como características

23 Idem. P. 63

24 FANON, 2008. P. 118-120 
inerentes à raça, reforçaria o mito de que os negros estacionaram em um estágio evolutivo superado pelos brancos. Tanto no racismo branco, quanto no antirracismo negro desta negritude há um fundamento comum: “(...) a verdade e o valor do homem estão contidos na raça. Em outras palavras, nos dois casos, a biologia suporta a cultura e dirige a história, tornando-as decorativas, em vez de práticas de atividades humanas”25.

Fanon defende que o negro não deve rejeitar a razão em detrimento da emoção, ao contrário, deve reivindicar a razão para si, que é algo inerente ao ser humano. Reivindicar a razão é defender a humanidade do negro, defender a essência humana que o racismo tenta lhe tirar. Portanto a luta contra o racismo deve ser travada no campo da razão. A afirmação de valores positivos para o negro deve tender ao universalismo. A antiguidade negra na África, e as complexas civilizações desenvolvidas neste continente são importantes para situar o negro na história da humanidade, e não para separá-lo. As culturas negras devem ser reconhecidas, sobretudo, enquanto culturas, sem o marcador étnico. A saída para o racismo está em colocar o negro em condição de igualdade com o branco no contexto universalista (superando o pretenso universalismo eurocêntrico). A luta do negro contra o racismo e o colonialismo é pela conquista do reconhecimento de sua essência humana, e não de uma suposta essência negra: o branco deve reconhecer a humanidade do negro. Deve haver um reconhecimento recíproco entre os diferentes grupos humanos, que não pode ser unilateral como ocorre em sociedades racistas onde apenas o grupo dominante é reconhecido ${ }^{26}$. A superação do que o autor define como condição neurótica onde o negro está aprisionado em sua "inferioridade” e o branco em sua "superioridade” deve ser superada através da luta, da transformação das condições materiais onde tais relações assimétricas se produzem. Com uma visão humanista e universalista Fanon defende a universalidade das lutas contra todas as formas de opressão que tem em comum a humanidade como objeto.

25 MUNANGA. P. 79

26 FANON, 2008. P. 180-181 


\section{REFERÊNCIAS BIBLIOGRÁFICAS}

FANON, Frantz. Os condenados da Terra. Minas Gerais: Editora UFJF, 2010.

. Pele negra, máscaras brancas. Bahia: Editora Edufba, 2008.

GORDON, Lewis R., "Prefácio.” in: FANON, Frantz, Pele negra, máscaras brancas. Bahia: Editora Edufba, 2008.

GUIMARÃES, Antonio Sérgio A., “A recepção de Fanon no Brasil e a identidade negra.” in: Novos Estudos, 8 de julho de 2008.

MUNANGA, Kabengele. Negritude: usos e sentidos. São Paulo, Editora Autentica, 2009.

SILVEIRA, Renato da, "Nota do tradutor." in: FANON, Frantz, Pele negra, máscaras brancas. Bahia, Edufba, 2008. 